\title{
An Examination of Alkali-Exchanged BEA Zeolites as Possible Lewis-Acid
}

\section{Catalysts}

Jingye Yu ${ }^{\mathrm{a}}$, Jing Luo ${ }^{\mathrm{a}}$, Yiwei Zhang ${ }^{\mathrm{a}, \mathrm{c}}$, Junjie Cao ${ }^{\mathrm{a}}$, Chun-Chih Chang ${ }^{\mathrm{b}}$, R. J. Gorte ${ }^{* a}$ and Wei Fan $^{* b}$

${ }^{a}$ Department of Chemical \& Biomolecular Engineering

University of Pennsylvania

Philadelphia, PA 19104, United States

${ }^{\mathrm{b}}$ Department of Chemical Engineering, University of Massachusetts

159 Goessmann Lab, 686 North Pleasant Street

Amherst, MA 01003-3110, United States

${ }^{\mathrm{c} S c h o o l}$ of Chemistry and Chemical Engineering, Southeast University, Nanjing 211189,

P.R.China

\begin{abstract}
The possibility of using alkali-exchanged BEA zeolites as Lewis-acid catalysts was examined using temperature-programmed desorption (TPD)/thermogravimetric analysis (TGA) measurements of adsorbed pyridine, 2-propanamine, diethyl ether, 2-methyl-2-propanol, and acetonitrile, FTIR of pyridine and $\mathrm{CD}_{3} \mathrm{CN}$, calorimetry of $\mathrm{CO}$, and reaction rates for reductive etherification of 5-hydroxymethyl furfural (HMF) with 2-propanol. Adsorption on the alkali cations occurs through ion-dipole interactions, as evidenced by the fact that adsorption is strongest on $\mathrm{Li}$, followed by $\mathrm{Na}$ and $\mathrm{K}$. Adsorption of all the probe molecules was much stronger on Li-BEA than on acid sites formed by framework Sn in SnBEA; however, the alkali-exchanged BEA samples were not catalytically active for alcohol dehydration or reductive etherification of HMF. The implications of these results for the characterization of solid Lewis acidity are discussed.

Keywords: Lewis Acidity; Alkali-Exchanged Zeolites; Calorimetry; FTIR; Temperature Programmed Desorption.

E-mails: yujingye@seas.upenn.edu; gorte@seas.upenn.edu *Corresponding Author: Raymond J. Gorte Phone: 215-898-8351 Fax: 215-573-2093 Address: Department of Chemical and Biomolecular Engineering, University of Pennsylvania, 311A Towne Building, 220 S. $33^{\text {rd }}$ Street, Philadelphia, PA 19104, USA
\end{abstract}




\section{Introduction}

There has recently been a great deal of interest in the development of solid Lewis acids for the processing of complex organic molecules, particularly for reactions involving biomass, [1-6]. Solid Lewis acids selectively catalyze a number of important reactions that are not effectively carried out by Brønsted acids, such as glucose-fructose isomerization [7] and the Meerwein-Ponndorf-Verley (MPV) reactions [8,9]. Some solid Lewis acids, such as $\mathrm{TiO}_{2}[10]$ and ceria [11], are even effective in water. One of the big advances in the development of solid Lewis acids has come from the recognition that highly active catalytic sites can be formed by framework substitution of metals like $\operatorname{Sn}[9,12,13]$, Ti [14,15], $\operatorname{Zr}[3,16]$, and $\mathrm{Hf}[16]$ into siliceous zeolites. Unfortunately, many of these materials can be difficult to synthesize and characterize. Although great progress has been made in our understanding of these metalsubstituted zeolites [17,18], there are still questions about the exact nature of the active sites.

It is noteworthy that gas-phase alkali cations "are generally considered as archetypal Lewis acids because the full positive charge of the naked cation allows strong binding with classical Lewis bases [19]". This leads to the question whether simple, alkali-exchanged zeolites might be used as solid Lewis acids. It is known that the hydrogen forms of zeolites have Brønsted-acid sites with characteristics that are very different from solution-phase Brønsted acids due in part to the fact that solvent interactions with the protonated base are limited by the nanopore structure of the zeolite. For example, for bases with proton affinities greater than that of ammonia, heats of adsorption at zeolite Brønsted sites tend to scale in a nearly 1:1 manner with the proton affinities of the bases [20,21], while heats of protonation in solution-phase are much more dependent on the structure of the molecule and the solvent. One manifestation of this is that pyridine is a much weaker base than ammonia in aqueous solutions, while it has a much higher proton affinity and interacts much more strongly with Brønsted sites in zeolites [22]. Although alkali cations in solution would not be considered Lewis acids, the environment in the zeolite pores could reduce solvent effects in the alkali-exchanged materials so that alkali cations could interact with Lewis bases in a similar manner to that observed in the gas phase.

However, alkali-exchanged zeolites are normally thought of as basic materials; and, in agreement with this, alkali-exchanged faujasites have been shown to exhibit catalytic properties that correlate with the basicity of the alkali hydroxide [23-26]. For example, Li, et al [24] found that the condensation of propionic acid and formaldehyde to form methacrylic acid increased 
with the basicity of the cation, with $\mathrm{NaX}<\mathrm{KX}<\mathrm{CsX}$. The properties in this case would appear to be dominated by the basicity of the framework oxygens. While this may be a general feature in zeolites, it should be recognized that many of the alkali cations in the faujasite structure will not be accessible to adsorbates, depending on the cation size and the $\mathrm{Si} / \mathrm{Al}$ ratio of the zeolite $[27,28]$. By contrast, all of the cations should be accessible to adsorbates in high-silica zeolites like BEA and MFI and these cations should exhibit Lewis-acid character, even if the oxygens are basic. There is indeed evidence that this may sometimes occur. For example, Huang and Kaliaguine reported that alkali-exchanged ZSM-5 was active for the transformation of propene to aromatics and the dehydrogenation of cyclohexane [29]. Tago, et al [30] found that activity of alkali-ion-exchanged BEA zeolites for the production of isobutylene from acetone followed the order of the acidity of the cations. Other evidence that alkali cations in solids could have Lewisacid character comes from a recent study that showed encapsulated $\mathrm{Li}^{+}$ions in $\mathrm{C}_{60}$ are active catalysts for the Diels-Alder reactions [31].

In the present work, we set out to investigate more completely the idea that alkaliexchanged BEA zeolites could be used as Lewis-acid catalysts and to compare the nature of the sites to those formed in SnBEA. We will show that, based on studies of selected probe molecules on Li-, Na-, and K-exchanged BEA zeolites, adsorption is dominated by interactions with the alkali cations. Based on pyridine adsorption, Li-BEA would appear to be as strong a Lewis acid as SnBEA; however, the reactivities of selected probe molecules in TPD measurements suggest that the alkali-exchanged zeolites are not good catalysts, a result that is confirmed by the lack of reaction between 5-hydroxymethyl furfural (HMF) and 2-propanol in flow-reactor measurements.

\section{Experimental}

Temperature Programmed Desorption (TPD) and Thermogravimetric Analysis (TGA) experiments were carried out using a CAHN 2000 microbalance mounted within a vacuum chamber that could be evacuated with a diffusion pump [32]. The base pressure of the system was $1 \times 10^{-5} \mathrm{~Pa}$. During TPD-TGA measurements, the sample weights were recorded continuously using the microbalance and the desorbing species were monitored using an SRI quadrupole mass spectrometer (RGA100). The heating rate for TPD-TGA experiments was $10 \mathrm{~K} / \mathrm{min}$. Unless otherwise noted, the samples were heated in vacuum to $773 \mathrm{~K}$, then cooled to room temperature in vacuo, prior to exposing them to a few hundred $\mathrm{Pa}$ of the adsorbate of interest. The system was then evacuated between 1 and $2 \mathrm{~h}$ before beginning each TPD-TGA experiment. 
FTIR spectra were collected on a Mattson Galaxy FTIR with a diffuse-reflectance attachment (Collector $\mathrm{II}^{\mathrm{TM}}$ ) purchased from Spectra-Tech Inc. Spectra were collected at $4 \mathrm{~cm}^{-1}$ resolution. The samples were initially calcined to $773 \mathrm{~K}$ in a separate system, transferred in air to the FTIR cell, and then heated again to $473 \mathrm{~K}$ in flowing $\mathrm{He}$ at $0.5 \mathrm{~cm}^{3} / \mathrm{s}$ to remove adsorbed water. After cooling the samples to room temperature, acetonitrile- $d 3$ or pyridine vapors were exposed to the sample, with the excess adsorbate then flushed from the solid using flowing He at $1 \mathrm{~cm}^{3} / \mathrm{s}$.

The reactions of HMF with 2-propanol were carried out in a high-pressure, flow reactor that has been described in detail elsewhere [32]. The tubular reactor was a 20-cm long, stainlesssteel tube with a 4-mm ID and 1/4-inch OD, passed through a tube furnace. The liquid feed, a mixture of 1 g HMF (99\%, Sigma-Aldrich) and 100 mL 2-propanol (99.9\%, Fisher Scientific), was introduced into the reactor using an HPLC pump (Series I+, Scientific Systems Inc). The reactor pressure was maintained at 69 bar using a back-pressure regulator (KPB series, Swagelok), and product analysis was carried out by means of a GC-Mass Spectrometer (QP5000 , Shimadzu). For the present studies, we used a fixed feed rate of $0.2 \mathrm{ml} / \mathrm{min}$. The measurements were performed using $0.1 \mathrm{~g}$ of each catalyst at $453 \mathrm{~K}$ to determine the effect of temperature and catalyst loading on conversion and selectivity. There was no reaction in the absence of a catalyst.

The calorimeter is a home-built, Calvet-type instrument that has been described in previous work [33]. The calorimeter itself consisted of a 5-kg Al block with cubical hole cut into the top to allow insertion of the sample cell, which was a pyrex cube, $2.54-\mathrm{cm}$ on a side. The sample could be evacuated with a mechanical pump and exposed to gas doses using a GC sampling valve and dosing loop. The pressure over the sample before and after exposure to gas doses was measured with a strain-gauge manometer. To measure the heat given off upon adsorption of a gas, five square thermal-flux meters (International Thermal Instrument Company, Del Mar, CA) were placed between the pyrex cell and bottom and sides of the cubical hole in the Al block. A silicone-based, heat-sink compound was used to make sure that there was good thermal contact between the Al block and the transducers and between the transducers and the pyrex cells. The zeolite samples in these studies were approximately $1 \mathrm{~g}$ of powder, pressed into wafers and spread over the bottom of the pyrex cell. Quartz chips were placed over the sample to 
prevent radiation losses. In all of the present work, the Al block was placed in a Styrofoam cooler with dry ice to maintain the sample temperature at $195 \mathrm{~K}$.

Most of the samples used in this study were based on $\mathrm{NH}_{4}$-BEA (Zeolyst International, \#CP814E; $\left.\mathrm{Si}_{\mathrm{Al}} \mathrm{Al}_{2}=24\right)$. The Brønsted-site density of the hydrogen form of the BEA zeolite, determined from the amount of 2-propylamine which reacted to propene and ammonia between 575 and $650 \mathrm{~K}$ in TPD-TGA [34], was found to be $650 \mu \mathrm{mol} / \mathrm{g}$. Based on the ${ }^{27} \mathrm{Al}$ MAS NMR spectrum of the fully hydrated sample, obtained using a Bruker DSX-300 NMR spectrometer at $\mathrm{a}^{27} \mathrm{Al}$ frequency of $78.2 \mathrm{MHz}$ with a $7 \mathrm{~mm}$ MAS probe, the non-framework $\mathrm{Al}$ was $14 \%$ of the total.

To generate the alkali forms of the BEA zeolite, $1 \mathrm{~g}$ of the $\mathrm{NH}_{4}{ }^{+}$form of the BEA was exchanged with a $300 \mathrm{~mL}$ solution that was $0.1 \mathrm{M} \mathrm{LiCl}(\mathrm{NaCl}, \mathrm{KCl})$ and $0.005 \mathrm{M} \mathrm{LiOH}(\mathrm{NaOH}$, $\mathrm{KOH}$ ) for $4 \mathrm{~h}$ at room temperature. That this procedure resulted in complete exchange to the alkali forms of the zeolite was demonstrated by the fact that calcined forms of the alkaliexchanged samples showed no evidence for Brønsted sites by either FTIR of adsorbed pyridine or TPD-TGA of adsorbed 2-propanamine.

The siliceous BEA (designated here as SiBEA) was made by stirring a commercial BEA (Zeolyst, $\mathrm{CP} 814 \mathrm{C}, \mathrm{Si} / \mathrm{Al}_{2}=38$ ) in $7-\mathrm{M}$ nitric acid for $8 \mathrm{~h}$ at $353 \mathrm{~K}$. The sample was then filtered and dried overnight at $333 \mathrm{~K}$. ICP-AES analysis of this sample showed that the bulk $\mathrm{Si} / \mathrm{Al}_{2}$ ratio was greater than 2500. In TPD-TGA measurements on this sample, the adsorption uptakes in the presence of 2-propylamine vapor were similar to that obtained on the unmodified H-BEA zeolite, indicating that the pore structure remained intact. In agreement with the high $\mathrm{Si} / \mathrm{Al}_{2}$ ratio, the Brønsted-site density was undetectable $(<5 \mu \mathrm{mol} / \mathrm{g})$ and the loss of framework $\mathrm{Al}$ from the structure caused this material to have a high concentration of hydroxyl defects.

The SnBEA used for comparison in the reaction and adsorption studies had a $\mathrm{Si} / \mathrm{Sn}$ ratio of 118 and was prepared by the procedure described by Corma et al [9]; characterization of this material has been described in detail elsewhere [3,35]. Because the SnBEA was made in a fluoride-containing medium, the defect site density was very low and the material was highly hydrophobic.

\section{Results}

\section{Calorimetric Investigation of $\mathrm{CO}$}


To better understand the nature of the Lewis sites generated by alkali cations in BEA, we performed calorimetric experiments using CO adsorption at $195 \mathrm{~K}$. CO is a weak Lewis base, with gas-phase affinities for $\mathrm{Li}^{+}, \mathrm{Na}^{+}$, and $\mathrm{K}^{+}$of 55, 33, and $19 \mathrm{~kJ} / \mathrm{mol}$, respectively [19]. Of critical importance for interpretation of the experimental results is that $\mathrm{CO}$ adsorption is reversible at $195 \mathrm{~K}$. Reversible adsorption is essential in microcalorimetry for ensuring that the molecules sample all sites in the catalyst, filling the strongest sites first, and that the molecules do not simply adsorb chromatographically at the first site with which they come in contact [36]. If adsorption is chromatographic and irreversible, the measured heats will appear to be constant up to the saturation coverage and there will be no possibility for measuring site distributions. Chromatographic adsorption is almost certainly a major problem with adsorption of strong bases, like pyridine and ammonia, on acidic zeolites [36].

In a previous study of $\mathrm{CO}$ adsorption on Li-exchanged MFI zeolites [33], the differential, isosteric heats of adsorption $(-\Delta \mathrm{H})$ were found to be $36 \mathrm{~kJ} / \mathrm{mol}$ at low coverages, decreasing to $\sim 17 \mathrm{~kJ} / \mathrm{mol}$ for coverages well in excess of one per cation. Because the heats of adsorption for $\mathrm{CO}$ on a siliceous MFI were $\sim 17 \mathrm{~kJ} / \mathrm{mol}$ and nearly independent of coverage, the heats in excess of this value can almost certainly be assigned to interactions with the Li cations. The zerocoverage heats were lower for Na-MFI (33 kJ/mol) and K-MFI (28 kJ/mol), and there was also evidence that more than one $\mathrm{CO}$ molecule could interact with these larger cations. Finally, it is worth noting that the heats of adsorption for $\mathrm{O}_{2}$ on both siliceous MFI and Li-MFI were also $\sim 17$ $\mathrm{kJ} / \mathrm{mol}$. This fact is useful since it demonstrates that $\mathrm{O}_{2}$ does not have significant interactions with the cations but interacts with the siliceous walls of the zeolite in a similar manner to that of $\mathrm{CO}$. This implies that heats of adsorption for $\mathrm{O}_{2}$ can be used to abstract that component of the $\mathrm{CO}$ adsorption heats due to interactions with the siliceous walls of the zeolite.

The heats of adsorption for CO on the alkali-exchanged BEA and SnBEA samples at 195 $\mathrm{K}$ are shown in Figure 1, together with results for $\mathrm{O}_{2}$ on $\mathrm{Li}-\mathrm{BEA}$. The results are very similar to what was observed on the MFI zeolites. Within experimental error, the zero-coverage heats for $\mathrm{CO}$ on the alkali-exchanged BEA were the same as what was observed on the MFI zeolites, with zero-coverage heats of $37 \mathrm{~kJ} / \mathrm{mol}$ on Li-BEA, $34 \mathrm{~kJ} / \mathrm{mol}$ on $\mathrm{Na}-\mathrm{BEA}$, and $26 \mathrm{~kJ} / \mathrm{mol}$ on K-BEA. The differential heats for $\mathrm{O}_{2}$ on Li-BEA were $\sim 15 \mathrm{~kJ} / \mathrm{mol}$, slightly lower than was observed on Li-MFI; but this is reasonable since BEA is a larger-pore zeolite and heats of adsorption for physically adsorbed molecules decrease with pore size [33]. For CO adsorption on Li-BEA at 
coverages above $800 \mu \mathrm{mol} / \mathrm{g}$, the heats of adsorption approached the value observed for $\mathrm{O}_{2}$, implying that molecules above one per Li are unable to approach the Li cations. The transition between the low- and high-energy states is gradual due to entropic effects [36]. On Na-BEA and

K-BEA, the heats are initially lower than those found on Li-BEA but the heats remain elevated to much higher CO coverages. Based on molecular sizes [33], multiple CO molecules can interact with these cations simultaneously.

What is perhaps most surprising about the data in Figure 1 is that the heats of adsorption for $\mathrm{CO}$ in SnBEA varied from 15 to $13 \mathrm{~kJ} / \mathrm{mol}$, essentially the same value one would expect for a siliceous BEA. Although the Sn site density was lower than the site densities in the alkali-BEA samples, it should have been possible to observe some evidence for adsorption on the Sn sites if interactions existed. Even in the absence of an ion-dipole interaction, one would expect additional van der-Waals interactions because of the higher Sn molecular weight. The result here suggests that the Sn cations are not accessible to CO molecules.

To summarize, several important conclusions can be drawn from the data in Figure 1. First, $\mathrm{CO}$ molecules clearly can interact with the cations in the alkali-exchanged BEA and the energetics of these interactions are significant. Second, the attractive interactions are strongest with $\mathrm{Li}$ and weakest with $\mathrm{K}$, in good correspondence with the gas-phase affinities of these ions and their expected Lewis acidity. Third, more than one CO molecule can interact simultaneously with the larger cations. Finally, the interaction between $\mathrm{CO}$ and framework-substituted Sn sites is very weak.

\section{Adsorption studies of 2-propylamine and pyridine}

Among the most common methods for characterizing solid acidity are TPD and FTIR measurements of pyridine or propylamines. TPD-TGA results for 2-propylamine on SiBEA, SnBEA, and the alkali-exchanged BEA samples are shown in Figure 2. The TGA data are reported as micromoles of 2-propylamine per gram of zeolite, referenced to the weight of the sample prior to exposure. All of the amine molecules on each of the samples desorbed as 2propanamine $(\mathrm{m} / \mathrm{e}=17,41,44)$. If any of the samples had contained Brønsted sites, there would have been a reaction to propene $(\mathrm{m} / \mathrm{e}=41)$ and ammonia $(\mathrm{m} / \mathrm{e}=17)$ between 575 and $650 \mathrm{~K}$ [21].

Although none of the samples contained Brønsted sites, it is still interesting to consider the desorption curves in more detail. For SiBEA, the initial coverage after exposure to the amine and 2 -h evacuation at room temperature was $850 \mu \mathrm{mol} / \mathrm{g}$. This adsorption is likely associated 
with amine molecules on silanol defect sites. The silanols are not strongly acidic, as demonstrated by the fact that all of the amine desorbed below $500 \mathrm{~K}$. On SnBEA, the initial amine coverage following adsorption and evacuation was slightly greater than $400 \mu \mathrm{mol} / \mathrm{g}$ and the TPD results showed two desorption features, centered at $\sim 390 \mathrm{~K}$ and $\sim 520 \mathrm{~K}$. The amount of 2-propanamine desorbing from the $520-\mathrm{K}$ feature appears to be $\sim 150 \mu \mathrm{mol} / \mathrm{g}$, which is close to expected Sn site density, $140 \mu \mathrm{mol} / \mathrm{g}$ based on a $\mathrm{Si} / \mathrm{Sn}$ ratio of 118 . Therefore, the hightemperature feature is likely associated with framework Sn sites. Because the concentration of silanol defects in this sample is expected to be very low, the $390-\mathrm{K}$ feature is likely due to amine molecules that are hydrogen-bonded to the molecules adsorbed at the Sn sites [37].

TPD-TGA results for each of the alkali-exchanged BEA samples also showed high initial coverages following evacuation and there were at least two peaks in desorption, at least from LiBEA and Na-BEA. The high-temperature peaks on Li-BEA (centered at $~ 580 \mathrm{~K}$ ) and Na-BEA (centered at $500 \mathrm{~K}$ ) corresponded to coverages that were close to the expected alkali site density of $650 \mu \mathrm{mol} / \mathrm{g}$. Additional features in the TPD below $500 \mathrm{~K}$ could be due to molecules that were hydrogen-bonded to the first molecule at the site or to the adsorption of multiple molecules at each site. With K-BEA, all of the 2-propanamine molecules desorbed below $500 \mathrm{~K}$, implying that there is weaker adsorption on the larger cations.

The TPD-TGA results for pyridine $(\mathrm{m} / \mathrm{e}=52)$ in Figure 3 lead to similar conclusions as those reached from 2-propanamine. Again, the initial coverage of pyridine on SiBEA following exposure to the vapor and evacuation was high, $\sim 1300 \mu \mathrm{mol} / \mathrm{g}$, but all of this desorbed below $450 \mathrm{~K}$. TPD-TGA on SnBEA again showed two peaks, centered at 400 and $550 \mathrm{~K}$, with the 550$\mathrm{K}$ feature corresponding to a coverage similar to that of the Sn site density. TPD-TGA on the alkali-exchanged BEA samples showed high initial coverages, between 1300 and $1500 \mu \mathrm{mol} / \mathrm{g}$. Although the desorption peaks were broad, there is a progressive decrease in the peak temperatures of the highest-temperature peaks, from nearly $600 \mathrm{~K}$ on Li-BEA to $\sim 520 \mathrm{~K}$ on NaBEA and $\sim 475 \mathrm{~K}$ on K-BEA. Clearly, there is an interaction between pyridine and the alkali cations and strength of this interaction decreases with increasing cation size.

The nature of the adsorbed pyridine on each of the samples was examined by FTIR, with the results shown in Figure 4. In each case, the spectra were obtained after exposure to pyridine vapor at room temperature, followed by flushing with dry He at $353 \mathrm{~K}$ to remove at least some of the physisorbed molecules. The spectrum for pyridine adsorbed on H-BEA is shown in spectrum 
i) for comparison. The peaks at $1546 \mathrm{~cm}^{-1}$ and $1489 \mathrm{~cm}^{-1}$ are due to pyridinium ions, showing that the pyridine has been protonated by Brønsted sites. The peak at $1450 \mathrm{~cm}^{-1}$, along with part of the intensity at $1489 \mathrm{~cm}^{-1}$, is likely due to additional physisorbed pyridine, perhaps bonded to the pyridinium ions. Spectrum ii), which was obtained on the dealuminated BEA sample with no Al, shows there is one major peak $1446 \mathrm{~cm}^{-1}$, with possibly a small band near $1490 \mathrm{~cm}^{-1}$, similar to a spectrum reported previously for pyridine on silica [38]. The SnBEA sample shows peaks at 1439 and $1484 \mathrm{~cm}^{-1}$, Spectrum iii), while spectra for the three alkali-exchanged BEA samples are reported in Spectra iv) through vi) and are virtually identical exhibiting bands between 1439 and $1442 \mathrm{~cm}^{-1}$ and between 1487 and $1492 \mathrm{~cm}^{-1}$.

There are certainly no major differences between the spectrum obtained on SnBEA and those spectra for the alkali-exchanged BEA samples. The peak positions are also very similar to what is observed on alumina, a known Lewis acid [39]. Whether the small changes one observes in the region between 1484 and $1492 \mathrm{~cm}^{-1}$ are significant is uncertain. There may be a systematic shift with increasing binding strength that correlates with binding strength on the alkaliexchanged materials, since the peak shifts from $1487 \mathrm{~cm}^{-1}$ on K-BEA to $1492 \mathrm{~cm}^{-1}$ on Li-BEA; however, pyridine also binds strongly on Sn sites in SnBEA and the peak position in that case is to $1484 \mathrm{~cm}^{-1}$. One obvious conclusion is that there is no clear correlation between acid strength and peak positions for Lewis acids in general or alkali-exchanged zeolites in particular.

\section{Adsorption studies of acetonitrile}

Acetonitrile has previously been found to be a useful molecule for probing Lewis acid sites in SnBEA [35,40]. TPD-TGA results for acetonitrile on SiBEA, SnBEA and alkaliexchanged BEA samples are shown in Figure 5. For SiBEA, the initial coverage after roomtemperature adsorption and evacuation was below $100 \mu \mathrm{mol} / \mathrm{g}$, much lower than the initial coverages in the case of 2-propylamine and pyridine. Meanwhile the TPD result shows no obvious desorption features. Results here suggest that adsorption of acetonitrile on silanols was extremely weak, making acetonitrile a good probe molecule to discriminate between Lewis acid sites and silanols. On SnBEA, initial coverage was between $80 \sim 100 \mu \mathrm{mol} / \mathrm{g}$ and desorption occurs in a peak centered at $400 \mathrm{~K}$. Because the coverage is less than the framework $\mathrm{Sn}$ concentration and desorption occurs at such low temperatures, the attraction between acetonitrile and framework Sn sites must be weak; some of the molecules adsorbed at Sn sites must have been removed during evacuation at room temperature. 
On the alkali-exchanged BEA samples, the initial coverages after evacuation were between $850 \mu \mathrm{mol} / \mathrm{g}$ and $1200 \mu \mathrm{mol} / \mathrm{g}$, higher than the alkali site densities, implying either that more than one molecule can be adsorbed on the same alkali cation site or that there is clustering of molecules at the site. Based on TPD results on Li-BEA, there is clear evidence for two desorption states, at $\sim 450$ and $550 \mathrm{~K}$, with the second corresponding to a coverage close to that of the Li site density, $650 \mu \mathrm{mol} / \mathrm{g}$. Desorption appears to occur in a single broad peak from Naand K-BEA but the peak temperature is higher on Na-BEA $(\sim 440 \mathrm{~K})$ compared to K-BEA $(\sim 410$ $\mathrm{K})$, implying that the strength of the interactions again decreases with cation size.

FTIR spectra of adsorbed $\mathrm{CD}_{3} \mathrm{CN}$ adsorbed on SnBEA and the three alkali-exchanged BEA samples are given in Figure 6. Again, spectra were acquired after exposure to $\mathrm{CD}_{3} \mathrm{CN}$ vapor at room temperature, followed by flushing with dry He at $353 \mathrm{~K}$. Previous reports demonstrated that $\mathrm{CD}_{3} \mathrm{CN}$ adsorbed on framework Sn sites exhibits a $\mathrm{v}(\mathrm{CN})$ stretch centered near $2310 \mathrm{~cm}^{-1}$ $[35,40]$. When $\mathrm{CD}_{3} \mathrm{CN}$ was present at higher coverages on Sn-BEA, additional vibration bands were observed at 2268 and $2276 \mathrm{~cm}^{-1}$, which were assigned to physisorbed acetonitrile and acetonitrile on silanols [40]. However, since IR spectra of acetonitrile on a BEA zeolite with only extraframework $\mathrm{SnO}_{2}$ showed only bands at 2263 and $2270 \mathrm{~cm}-1$ [35], the band at $2276 \mathrm{~cm}^{-1}$ may be associated with the framework Sn sites, perhaps as a second molecule hydrogen-bonded to the first. It is noteworthy that acetonitrile binds to Brønsted-acid sites with a similar energy as it does to framework Sn sites based on the fact that desorption peak temperatures in TPD are almost the same [35,37]; however, the $v(\mathrm{CN})$ vibrational stretch for $\mathrm{CD}_{3} \mathrm{CN}$ adsorbed at Brønsted-acid sites occurs at a significantly lower frequency, $2298 \mathrm{~cm}^{-1}$ [41]. Therefore, there is no simple relationship between the $v(\mathrm{CN})$ stretching frequency and binding strength.

Spectrum i) in Figure 6 was obtained on SnBEA. In basic agreement with past work, there were two bands at 2270 and $2307 \mathrm{~cm}^{-1}$. The band at $2307 \mathrm{~cm}^{-1}$ can confidently be assigned to adsorption at framework Sn sites. The spectra for Li-BEA, Na-BEA and K-BEA, reported in ii) through iv), show only one peak. The peak positions for the $v(\mathrm{CN})$ stretch vary with cation size, decreasing from $2287 \mathrm{~cm}^{-1}$ for Li-BEA, to $2275 \mathrm{~cm}^{-1}$ for Na-BEA, and $2264 \mathrm{~cm}^{-1}$ for K-BEA. Although the peak position for the adsorbed $\mathrm{CD}_{3} \mathrm{CN}$ shifts with cation size and the apparent strength of interaction with those cations, there is no evidence for new peaks that can be clearly identified with adsorption on the cations. For the alkali cations, the shift in the $v(\mathrm{CN})$ stretch is 
likely due to the strength of the ion-dipole interactions and not any well-defined adsorption at a Lewis site.

\section{Adsorption of 2-Methyl-2-Propanol and Diethyl Ether}

In previous work characterizing Lewis acid sites in SnBEA, adsorption stoichiometries of one molecule per framework Sn site were observed in TPD-TGA measurements of diethyl ether and 2-methyl-2-propanol [35]. The framework Sn sites were also able to catalyze the dehydration of 2-methyl-2-propanol, making this an interesting probe molecule for understanding the nature of the acid sites.

TPD-TGA results for diethyl ether on the five samples are shown in Figure 7 and exhibit some similarities to the results for acetonitrile. Unlike previously published data for H-ZSM-5 [37], there is no evidence for reaction of the diethyl ether during TPD on any of the samples. For SiBEA, the initial coverage after adsorption and room-temperature evacuation was $500 \mu \mathrm{mol} / \mathrm{g}$, implying that there must be some interaction between the ether molecules and the silanol defects, but all of the molecules desorbed by $425 \mathrm{~K}$. On SnBEA, initial coverage after evacuation was $120 \mu \mathrm{mol} / \mathrm{g}$, slightly less than the framework Sn concentration. Again, because the coverage is less than the framework Sn concentration and desorption occurs at below $450 \mathrm{~K}$, the diethyl ether molecules must bind weakly to the framework Sn sites. Adsorption on the alkali-exchanged BEA samples was much stronger than that on the SiBEA and SnBEA samples. The initial coverages were between 800 and $1000 \mu \mathrm{mol} / \mathrm{g}$; and there was evidence for two adsorption states, at least for Li-BEA and Na-BEA. On Li-BEA, the two ether-desorption $(\mathrm{m} / \mathrm{e}=31)$ peaks were centered at $\sim 420$ and $540 \mathrm{~K}$. Since the ether coverage at $500 \mathrm{~K}$ was $\sim 650 \mu \mathrm{mol} / \mathrm{g}$, molecules desorbing from the 540-K peak must be associated with the Li-exchange sites. The results on Na-BEA were similar but the two desorption states were not clearly resolved, due to the fact that the second peak occurs at lower temperatures. On K-BEA, desorption is complete by $500 \mathrm{~K}$.

TPD-TGA data for 2-methyl-2-propanol on SiBEA, SnBEA, and three alkali-exchanged materials are given in Figure 8. After exposure to the vapor and evacuation on SiBEA, the coverage of 2-methyl-2-propanol remained above $600 \mu \mathrm{mol} / \mathrm{g}$, probably due to hydrogenbonding of the alcohol to silanol defects in the structure. All of this desorbs unreacted (2-Methyl2-propanol has a major peak at $\mathrm{m} / \mathrm{e}=59$ in its mass spectrum, with minor peaks at 18 and 56.) in a peak centered at $400 \mathrm{~K}$. It is interesting to note that, if the 2-methyl-2-propanol had been adsorbed on Brønsted sites, the dehydration reaction would have occurred at room temperature 
[34]. On SnBEA, the initial coverage was much lower, $250 \mu \mathrm{mol} / \mathrm{g}$, because of the lower defect concentration on this material. While some of the alcohol desorbs unreacted at $350 \mathrm{~K}$, an amount close to the site concentration of framework $\mathrm{Sn}$ reacts to butene $(\mathrm{m} / \mathrm{e}=56)$ and water $(\mathrm{m} / \mathrm{e}=18)$ in a peak at $400 \mathrm{~K}$, in close agreement with results reported previously [35]. Interestingly, 2methyl-2-propanol adsorbed on another Lewis acid, $\gamma-\mathrm{Al}_{2} \mathrm{O}_{3}$, reacts to butene and adsorbed water between 425 and $475 \mathrm{~K}$, implying that the Sn sites are more catalytically active than the Lewis sites on $\gamma-\mathrm{Al}_{2} \mathrm{O}_{3}[42]$ for reaction of this tertiary alcohol.

The initial coverages 2-methyl-2-propanol following adsorption and evacuation on alkaliexchanged BEA samples were all approximately $1200 \mu \mathrm{mol} / \mathrm{g}$, which is nearly two molecules per exchange site. This implies that there must be clustering of the alcohol molecules at those sites. On Li-BEA, unreacted 2-methyl-2-propanol desorbs in a broad peak centered at $450 \mathrm{~K}$, leaving approximately $650 \mu \mathrm{mol} / \mathrm{g}$ of the alcohol to react to butene and water between 500 and $550 \mathrm{~K}$. Because the tert-butyl cation is so stable and 2-methyl-2-propanol so reactive, it is unclear whether the reaction at higher temperatures is catalyzed by the site or simply an indication of the thermal stability of the alcohol. In either case, the Li sites are much less reactive than the framework $\mathrm{Sn}$ sites in SnBEA or the Lewis sites in $\gamma-\mathrm{Al}_{2} \mathrm{O}_{3}$, as indicated by the higher temperature required to initiate reaction. TPD-TGA results on Na-BEA and K-BEA are similar to that found on Li-BEA except that progressively less of the 2-methyl-2-propanol is held on the sample at $500 \mathrm{~K}$, so that less of the alcohol reacts.

\section{Liquid-Phase Reductive Etherification of HMF}

It has previously been shown that a wide range of solid Lewis acids are able to catalyze the reductive etherification of 5-hydroxylmethylfurfural (HMF) in 2-propanol to first produce 2,5-bis(hydroxymethyl)furan (BHMF) by the oxidation of 2-propanol to acetone, followed by subsequent reactions of the BHMF to the mono-ether (5-[(1-methylethoxy)methyl]-2furanmethanol, MEFA) or di-ether (2,5-bis[(1-methylethoxy)methyl]furan, BEF) [3] at high yields [32]. To determine whether the ion-exchanged BEA zeolites were able to catalyze this reaction, the liquid-phase reaction was performed on Li-BEA, K-BEA, SiBEA and SnBEA, with results shown in Table 1. These experiments were carried out at $453 \mathrm{~K}$ and 62 bar using the same amount of catalyst and the same liquid flow rates. A complete description of the results for SnBEA is given elsewhere; for the present, it is simply worth noting that the HMF conversion was $35.8 \%$ for the conditions that were used. On SiBEA, the conversion was $4.5 \%$, perhaps due 
to a small residual concentration of Al sites or to reaction on the nested-silanol defects. However, there was no observable reaction on either Li-BEA or K-BEA. For this reaction, the alkaliexchanged zeolites are not catalytically active.

\section{Discussion}

There are a number of interesting conclusions that can be drawn from this study. First, the alkali-exchanged zeolites are not good catalysts for either alcohol dehydration reactions or reductive etherification reactions. In retrospect, this is perhaps not surprising. The bonding in alkali-exchanged materials is ion-dipole in nature, as is clearly shown by the fact that adsorption was strongest on Li sites, followed by $\mathrm{Na}$ and $\mathrm{K}$. Ion-dipole interactions are expected to decrease with increasing ion size [19]. Since there is no possibility for coordination chemistry on the alkali cations, there is no possibility of accepting electrons and catalyzing reactions. The fact that framework Sn sites are catalytically active implies that these more complex interactions must be possible in that material, as has been shown in recent spectroscopic studies [35].

However, the results also clearly demonstrate that typical basic probe molecules, like pyridine, which are often used to characterize Brønsted and Lewis acidity, do indeed interact very strongly with alkali cations, especially Li. Strong adsorption is also observed with ethers and alcohols, which desorbed at much higher temperatures on the alkali-exchanged BEA samples than are observed on SnBEA. Adsorption strength in this case clearly does not correlate with catalytic activity. Using standard probe molecules, like ammonia and pyridine, to quantify site strengths should only be used on a set of similar materials because there is no clear relationship between adsorption strength and site activity. Even in this case, reactive probe molecules should probably be preferred, since there is a clearer relationship with catalytic chemistry.

An important implication of all this is that measurement of Lewis acidity is intrinsically difficult. This should not be surprising, given the fact that bonding between a Lewis acid and a Lewis base tends to be specific to the particular acid and base being considered. Even in the much simpler case of Brønsted acids, there is no simple relationship between adsorption energetics and catalytic activity [43]. For example, the heats of adsorption for ammonia and pyridine are the same at Brønsted sites formed by framework $\mathrm{Al}$ and by framework Fe in the MFI structure, even though the reactivity of these sites for alkane cracking and olefin oligomerization are very different [44]. While the idea of quantifying acidity by means of 
measuring heats of adsorption for a standard probe molecule is appealing, the situation is clearly more complex.

Obviously, we have not examined all possible reactions or reactive molecules and alkaliexchanged zeolites may be active catalysts for some specific cases. For example, alkaliexchanged zeolites have been reported to catalyze the dehydration of lactic acid to acrylic acid $[45,46]$. It is also possible that alkali cations may promote reactions at neighboring Brønsted sites. These kinds of interactions still need to be explored.

\section{Conclusions}

Alkali-exchanged BEA zeolites interact strongly with alcohols, amines, pyridine, and acetonitrile and can be consider Lewis acids on that basis. However, the adsorption bonding in these materials is due to ion-dipole interactions, as demonstrated by the fact that interactions are strongest with $\mathrm{Li}$, followed by $\mathrm{Na}$ and $\mathrm{K}$. Unfortunately, these materials were not catalytically active for reactions like alcohol dehydration or the reductive etherification of HMF.

\section{Acknowledgement}

We acknowledge support from the Catalysis Center for Energy Innovation, an Energy Frontier Research Center funded by the U.S. Department of Energy, Office of Science, Office of Basic Energy Sciences under Award (No. DE-SC0001004). Y. Z. acknowledges funding from the China Scholarship Council (No.201308320238).

\section{References}

[1] K. Shimizu, A. Satsuma, Energy Environ. Sci. 4 (2011) 3140.

[2] S. De, S. Dutta, A.K. Patra, B.S. Rana, A.K. Sinha, B. Saha, A. Bhaumik, Appl. Catal. Gen. 435-436 (2012) 197-203.

[3] J. Jae, E. Mahmoud, R.F. Lobo, D.G. Vlachos, ChemCatChem 6 (2014) 508-513.

[4] O. Casanova, S. Iborra, A. Corma, J. Catal. 275 (2010) 236-242.

[5] L. Bui, H. Luo, W.R. Gunther, Y. Román-Leshkov, Angew. Chem. 125 (2013) 8180-8183.

[6] R. Bermejo-Deval, R.S. Assary, E. Nikolla, M. Moliner, Y. Román-Leshkov, S.-J. Hwang, A. Palsdottir, D. Silverman, R.F. Lobo, L.A. Curtiss, others, Proc. Natl. Acad. Sci. 109 (2012) 9727-9732.

[7] M. Moliner, Y. Roman-Leshkov, M.E. Davis, Proc. Natl. Acad. Sci. 107 (2010) 6164-6168.

[8] M. Chia, J.A. Dumesic, Chem. Commun. 47 (2011) 12233.

[9] A. Corma, M.E. Domine, V. Susana, J. Catal. 215 (2003) 294-304.

[10] K. Nakajima, R. Noma, M. Kitano, M. Hara, J. Phys. Chem. C 117 (2013) 16028-16033.

[11] Y. Wang, F. Wang, Q. Song, Q. Xin, S. Xu, J. Xu, J. Am. Chem. Soc. 135 (2013) 15061515. 
[12] Y.R omán-Leshkov, M.E. Davis, ACS Catal. 1 (2011) 1566-1580.

[13] M.S. Holm, Y.J. Pagán-Torres, S. Saravanamurugan, A. Riisager, J.A. Dumesic, E. Taarning, Green Chem. 14 (2012) 702.

[14] R. Gounder, M.E. Davis, ACS Catal. 3 (2013) 1469-1476.

[15] R. Gounder, M.E. Davis, J. Catal. 308 (2013) 176-188.

[16] J.D. Lewis, S. Van de Vyver, A.J. Crisci, W.R. Gunther, V.K. Michaelis, R.G. Griffin, Y. Román-Leshkov, ChemSusChem 7 (2014) 2255-2265.

[17] P. Wolf, M. Valla, A.J. Rossini, A. Comas-Vives, F. Núñez-Zarur, B. Malaman, A. Lesage,

L. Emsley, C. Copéret, I. Hermans, Angew. Chem. 126 (2014) 10343-10347.

[18] R. Bermejo-Deval, M. Orazov, R. Gounder, S.-J. Hwang, M.E. Davis, ACS Catal. 4 (2014) 2288-2297.

[19] C. Laurence, J.-F. Gal, Lewis Basicity and Affinity Scales: Data and Measurement, John Wiley \& Sons, 2009.

[20] D. Parrillo, R. Gorte, W. Farneth, J. Am. Chem. Soc. 115 (1993) 12441-12445.

[21] R.J. Gorte, Catal. Lett. 62 (1999) 1-13.

[22] D. Parrillo, C. Lee, R. Gorte, Appl. Catal. Gen. 110 (1994) 67-74.

[23] E.A. Pidko, P. Mignon, P. Geerlings, R.A. Schoonheydt, R.A. van Santen, J. Phys. Chem. C 112 (2008) 5510-5519.

[24] J. Li, J. Tai, R.J. Davis, Catal. Today 116 (2006) 226-233.

[25] J.W. Ward, J. Catal. 10 (1968) 34-46.

[26] D. Barthomeuf, Catal. Rev. 38 (1996) 521-612.

[27] D.H. Olson, Zeolites 15 (1995) 439-443.

[28] T. Frising, P. Leflaive, Microporous Mesoporous Mater. 114 (2008) 27-63.

[29] J. Penzien, A. Abraham, J.A. van Bokhoven, A. Jentys, T.E. Müller, C. Sievers, J.A. Lercher, J. Phys. Chem. B 108 (2004) 4116-4126.

[30] T. Tago, H. Konno, S. Ikeda, S. Yamazaki, W. Ninomiya, Y. Nakasaka, T. Masuda, Catal. Today 164 (2011) 158-162.

[31] H. Ueno, H. Kawakami, K. Nakagawa, H. Okada, N. Ikuma, S. Aoyagi, K. Kokubo, Y. Matsuo, T. Oshima, J. Am. Chem. Soc. 136 (2014) 11162-11167.

[32] J. Luo, J. Yu, R.J. Gorte, E. Mahmoud, D.G. Vlachos, M.A. Smith, Catal. Sci. Technol. 4 (2014) 3074.

[33] S. Savitz, A.L. Myers, R.J. Gorte, Microporous Mesoporous Mater. 37 (2000) 33-40.

[34] T.G. Kofke, R. Gorte, W. Farneth, J. Catal. 114 (1988) 34-45.

[35] S. Roy, K. Bakhmutsky, E. Mahmoud, R.F. Lobo, R.J. Gorte, ACS Catal. 3 (2013) 573580 .

[36] D.J. Parrillo, R.J. Gorte, Thermochim. Acta 312 (1998) 125-132.

[37] C.-C. Lee, R.J. Gorte, W.E. Farneth, J. Phys. Chem. B 101 (1997) 3811-3817.

[38] H. Nakabayashi, Bull. Chem. Soc. Jpn. 65 (1992) 914-916.

[39] A.A. Khaleel, K.J. Klabunde, Chem.- Eur. J. 8 (2002) 3991-3998.

[40] M. Boronat, P. Concepcion, A. Corma, M. Renz, S. Valencia, J. Catal. 234 (2005) 111118.

[41] J. Kotrla, L. Kubelková, C.-C. Lee, R.J. Gorte, J. Phys. Chem. B 102 (1998) 1437-1443.

[42] P. Kostestkyy, J. Yu, R.J. Gorte, G. Mpourmpakis, Catal Sci Technol 4 (2014) 3861-3869.

[43] A.J. Jones, R.T. Carr, S.I. Zones, E. Iglesia, J. Catal. 312 (2014) 58-68.

[44] O. Kresnawahjuesa, G.H. Kuhl, R.J. Gorte, C.A. Quierini, J. Catal. 210 (2002) 106-115.

[45] P. Sun, D. Yu, Z. Tang, H. Li, H. Huang, Ind. Eng. Chem. Res. 49 (2010) 9082-9087. 
[46] B. Yan, L.-Z. Tao, Y. Liang, B.-Q. Xu, ChemSusChem 7 (2014) 1568-1578. 


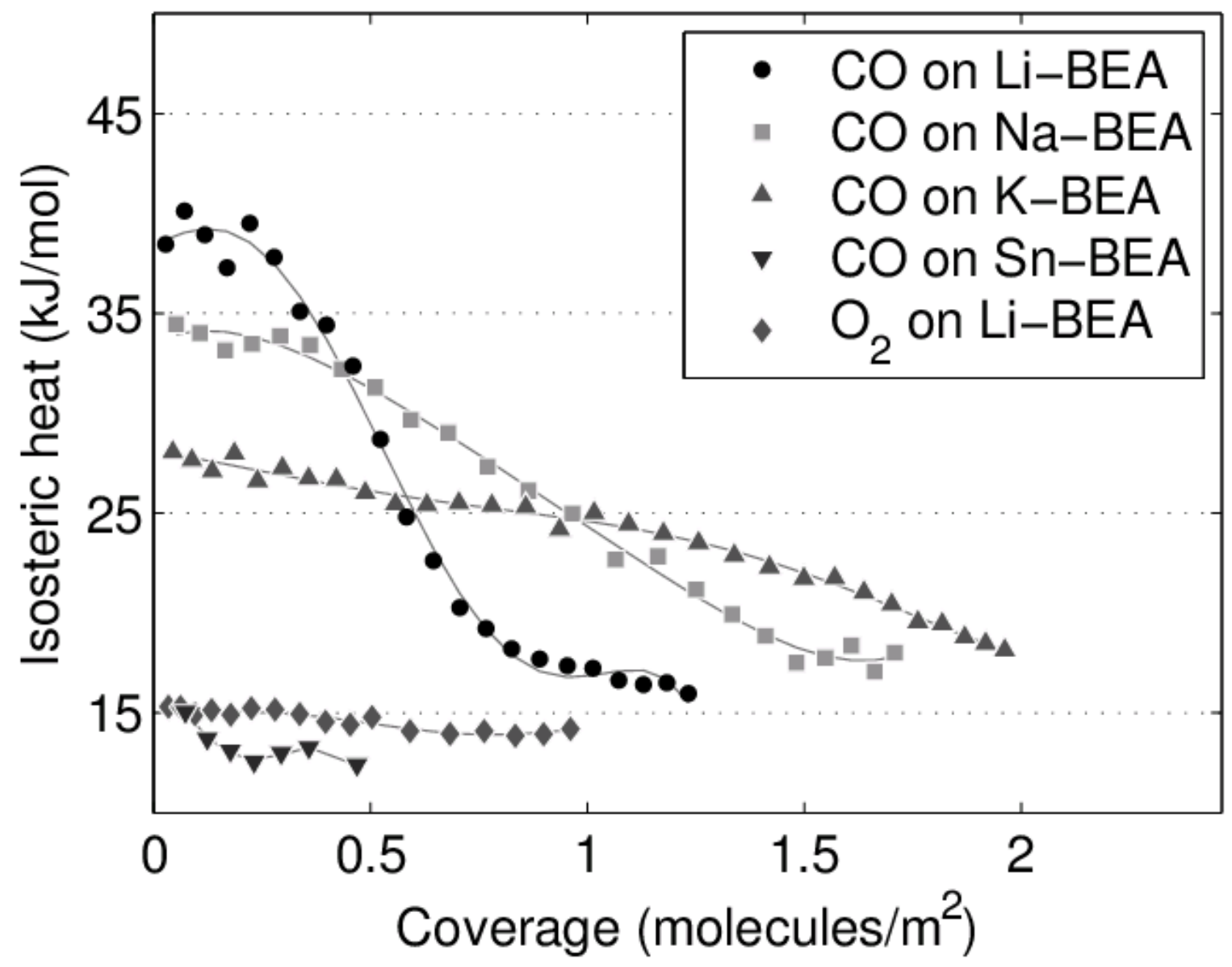

Figure 1. Calorimetric data for $\mathrm{CO}$ and $\mathrm{O}_{2}$ adsorption on Li-BEA and for $\mathrm{CO}$ on Na-BEA, K-BEA and SnBEA. The measurements were performed at $195 \mathrm{~K}$. 


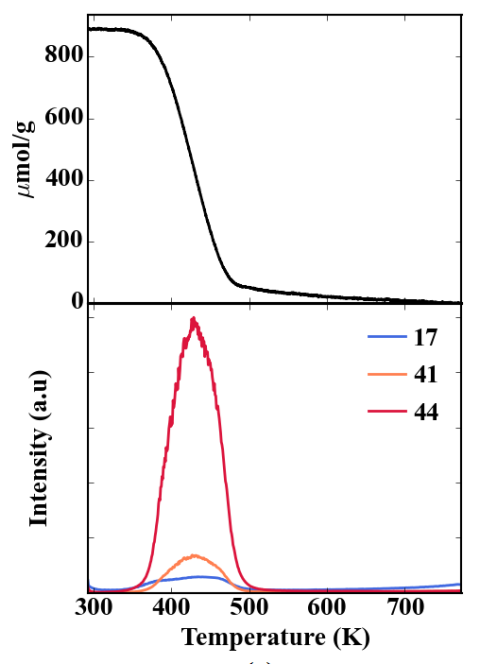

(a)

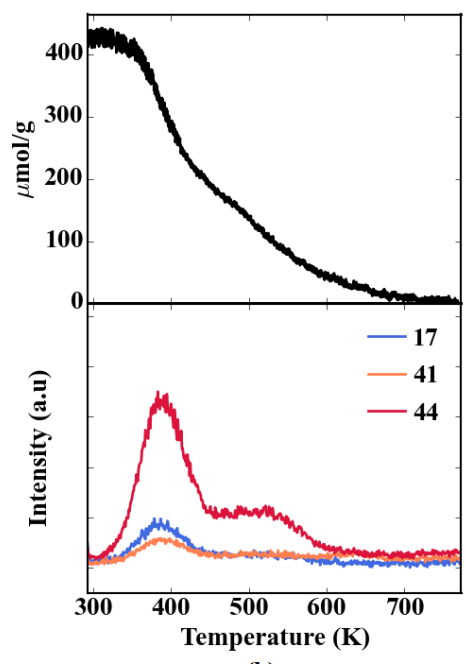

(b)

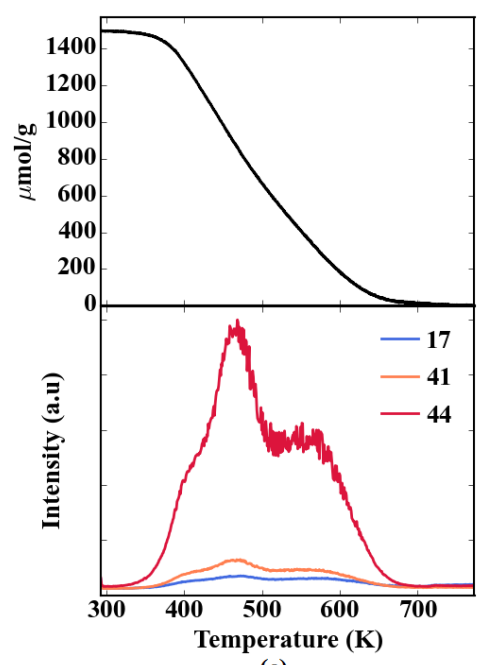

(c)

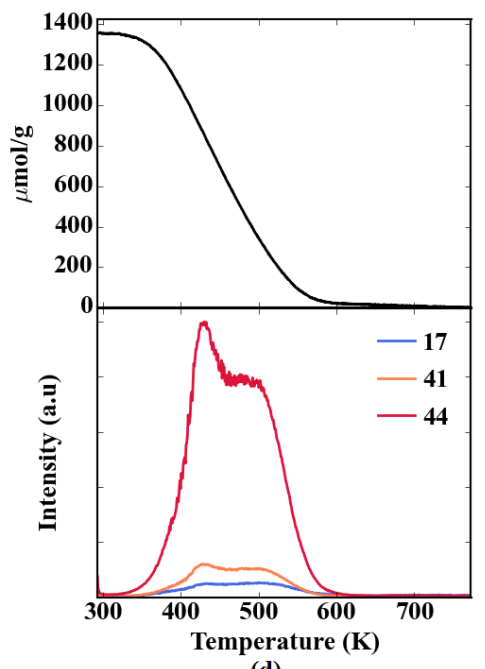

(d)

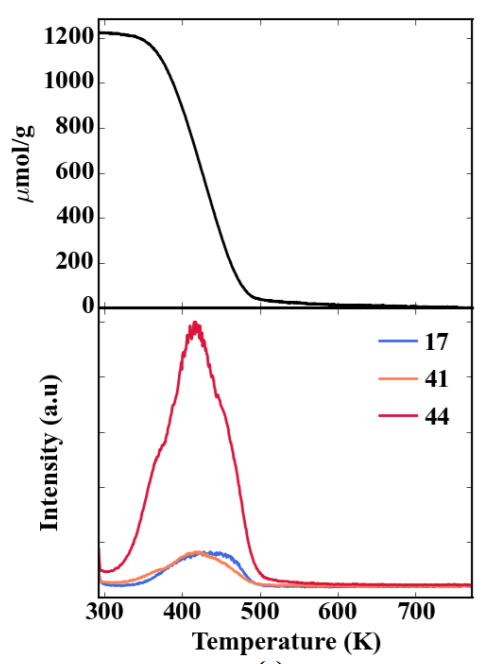

(e)

Figure2. TPD-TGA results for 2-propylamine on (a) SiBEA, (b) SnBEA (c) Li-BEA, (d) Na-BEA, and (e) K-BEA. 


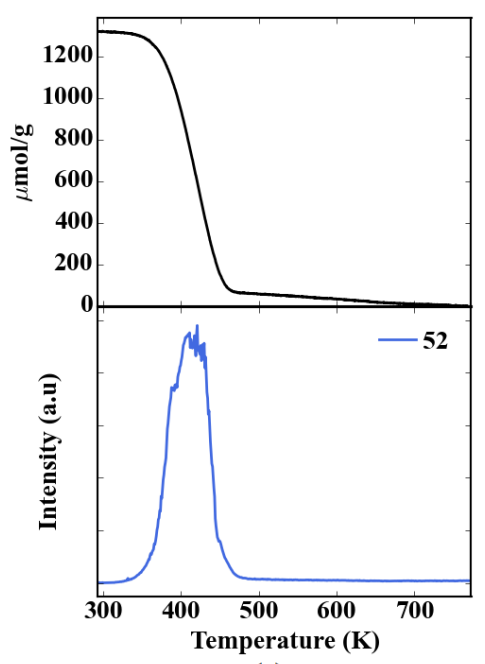

(a)

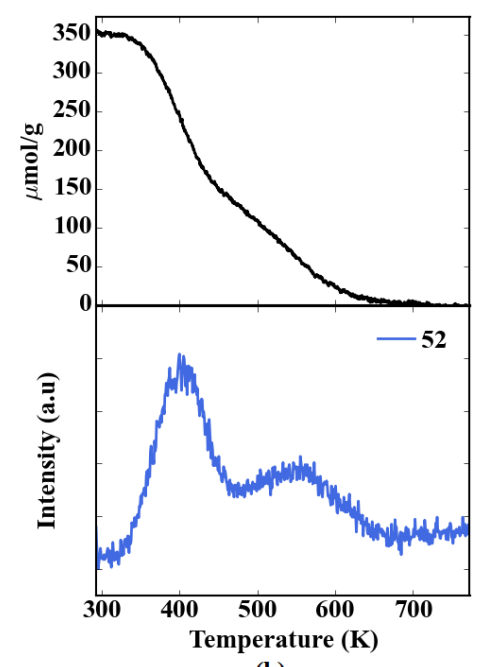

(b)

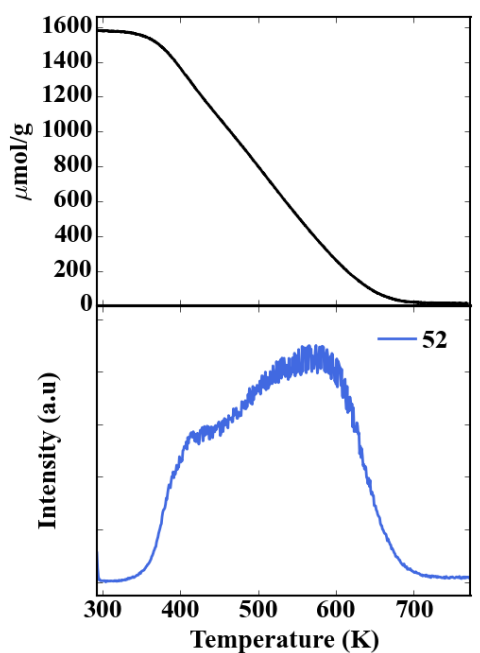

(c)

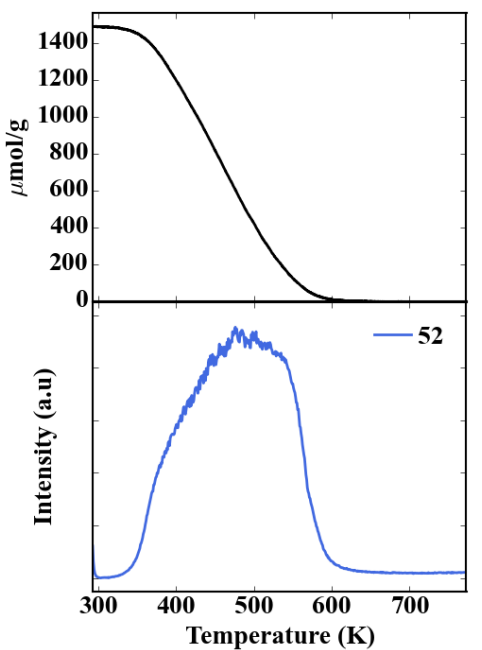

(d)

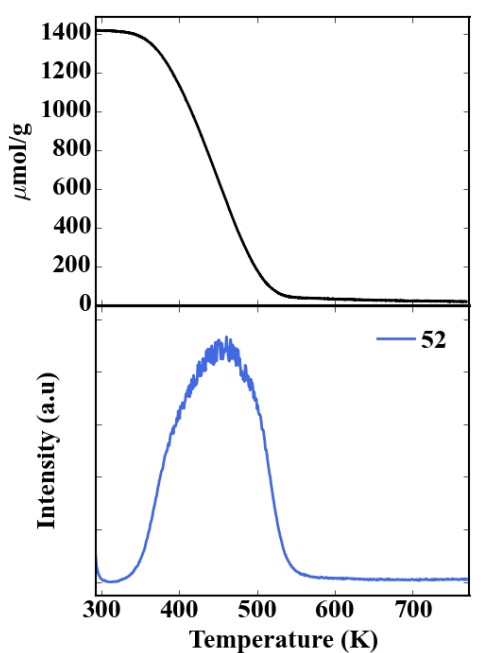

(e)

Figure 3. TPD-TGA results for pyridine on (a) SiBEA, (b) SnBEA (c) Li-BEA, (d) Na-BEA, and (e) KBEA. 


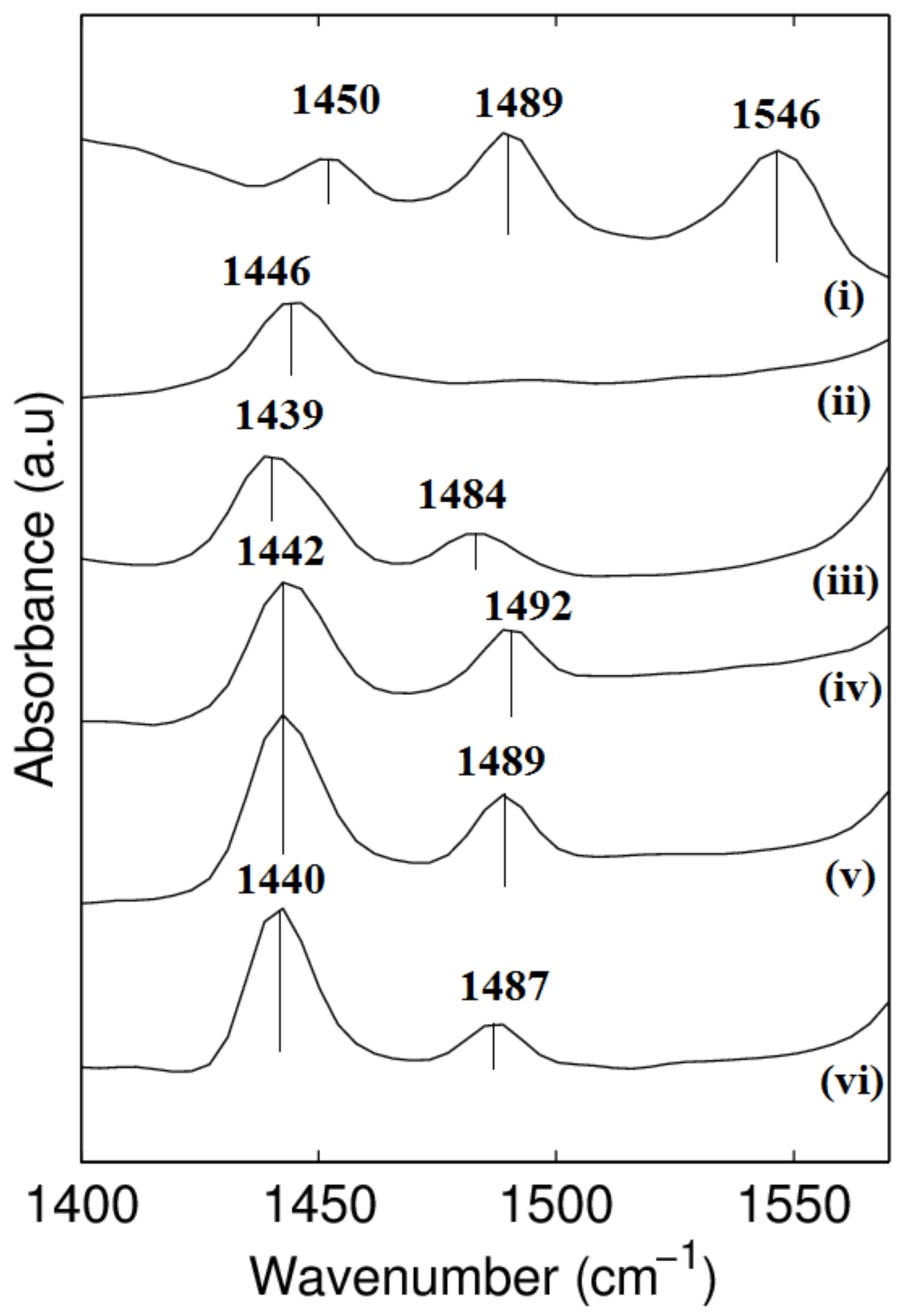

Figure 4. FTIR spectra of pyridine adsorbed on (i) H-BEA, (ii) SiBEA (iii) SnBEA (iv) Li-BEA, (v) NaBEA, and (vi) K-BEA. 


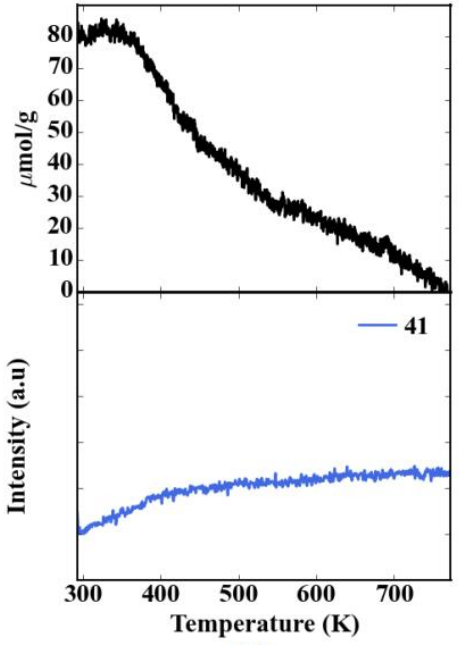

(a)

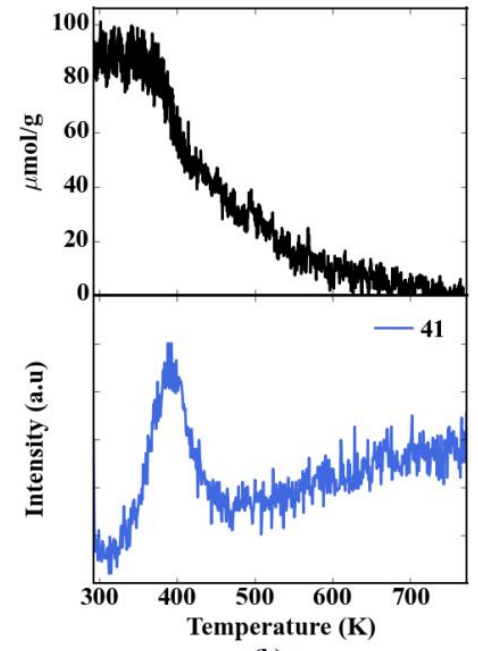

(b)

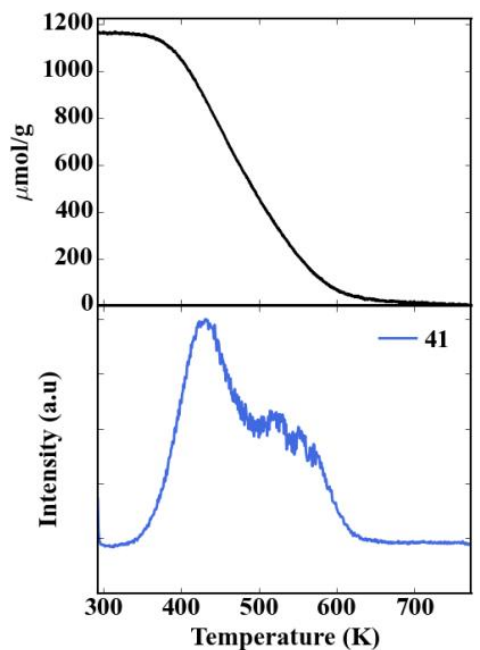

(c)

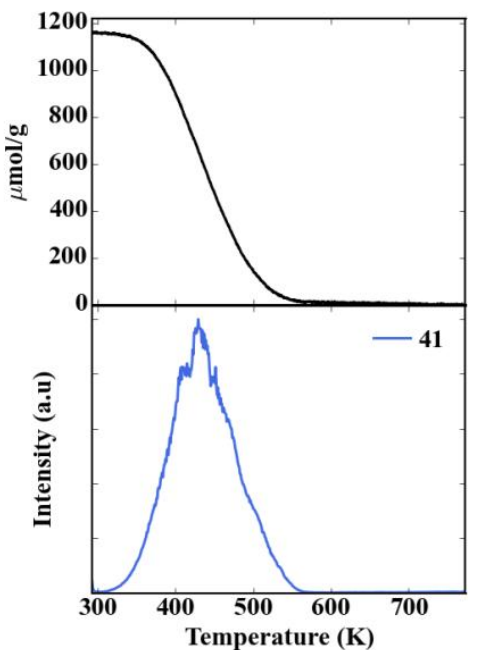

(d)

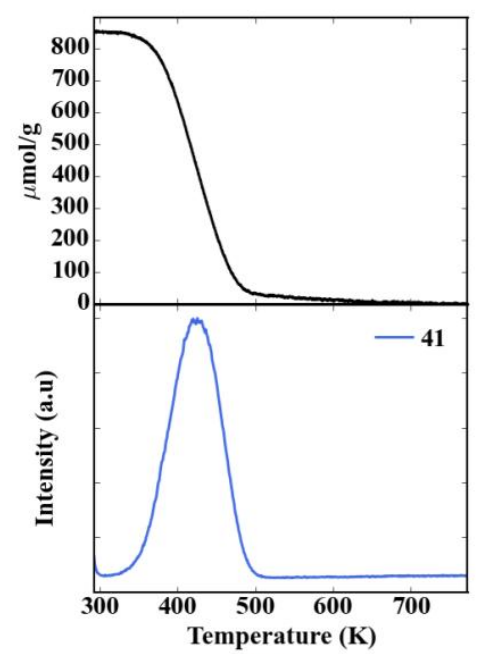

(e)

Figure 5. TPD-TGA results for acetonitrile on (a) SiBEA zeolite, (b) SnBEA (c) Li-BEA, (d) Na-BEA, and (e) K-BEA. 


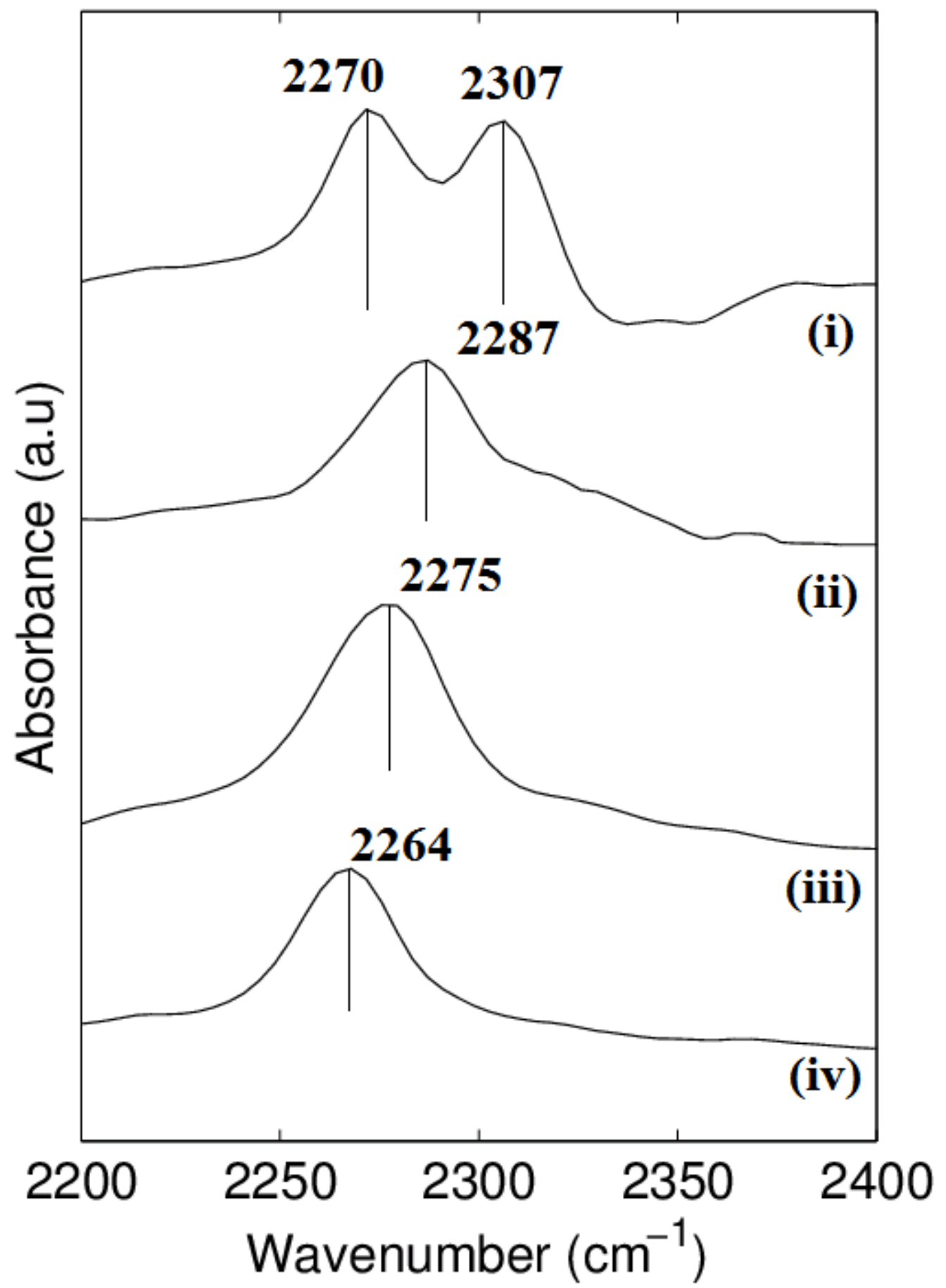

Figure 6. FTIR spectra of $\mathrm{CD}_{3} \mathrm{CN}$ adsorbed on (i) SnBEA, (ii) Li-BEA, (iii) Na-BEA, and (iv) K-BEA. 


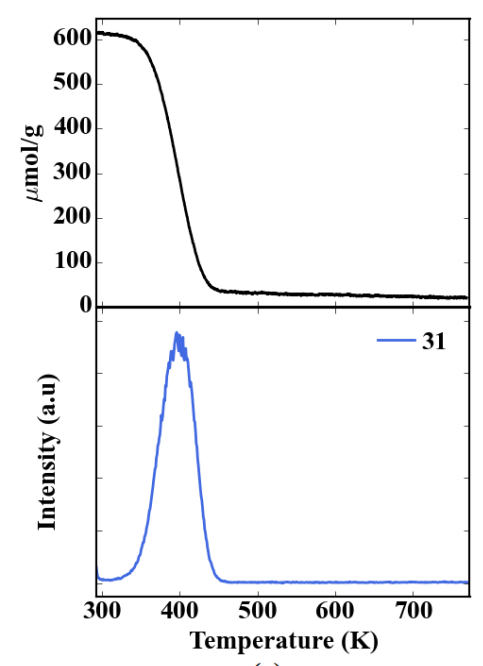

(a)

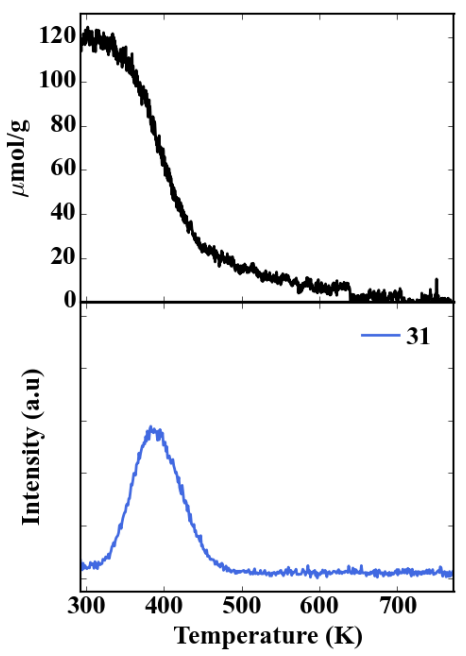

(b)

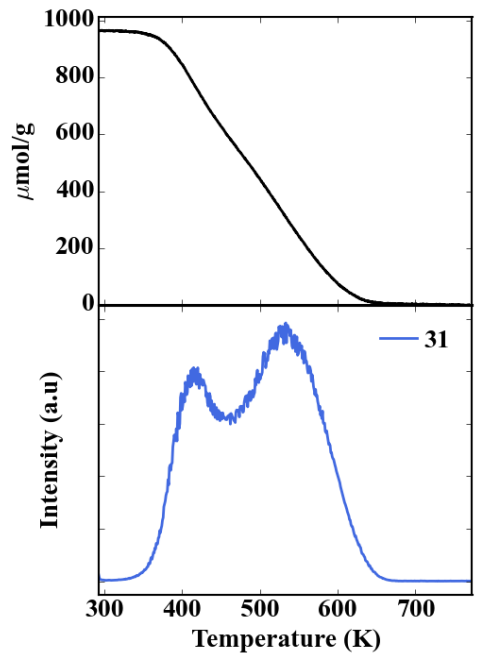

(c)

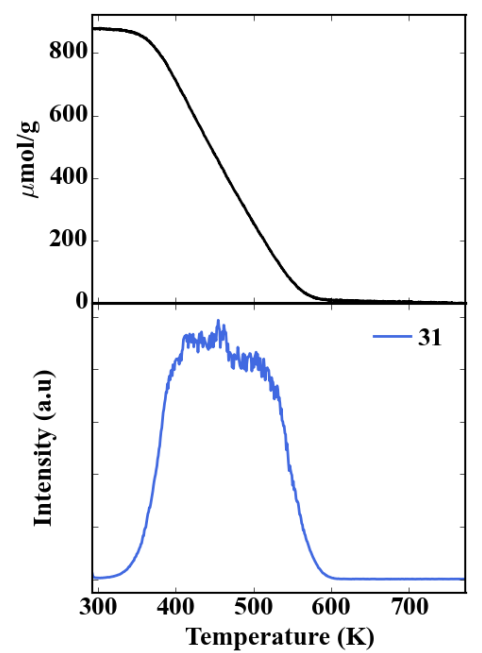

(d)

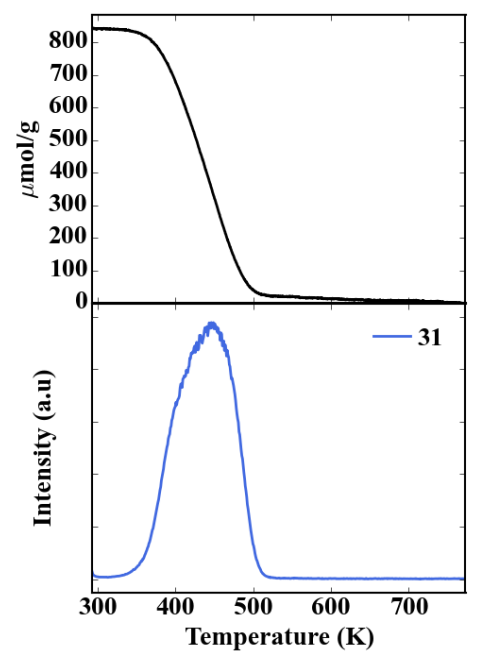

(e)

Figure 7. TPD-TGA results for diethyl ether on (a) SiBEA, (b) SnBEA (c) Li-BEA, (d) Na-BEA, and (e) K-BEA. 


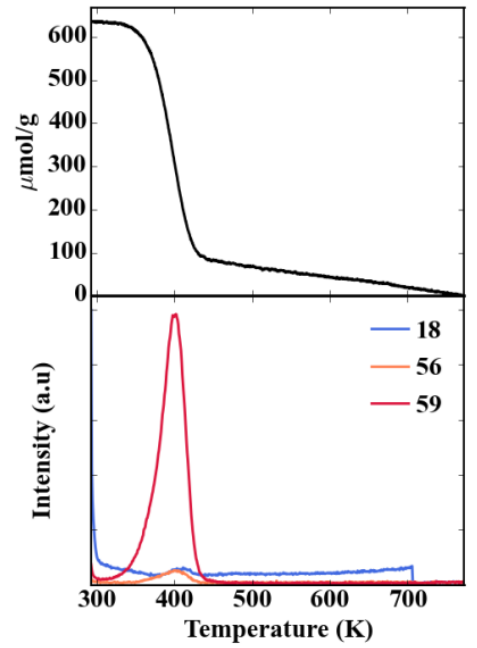

(a)

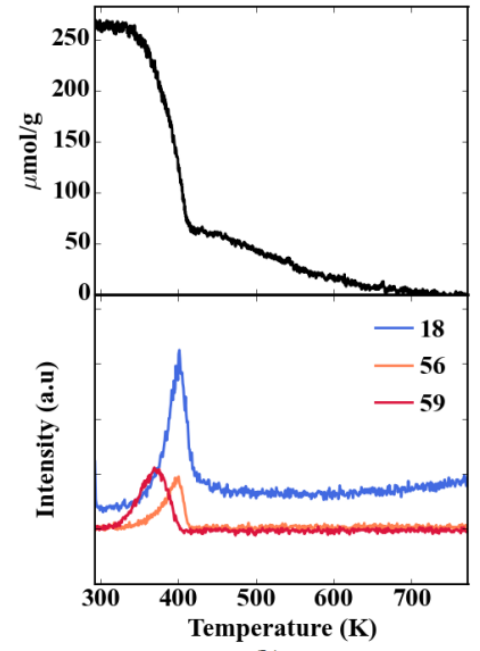

(b)

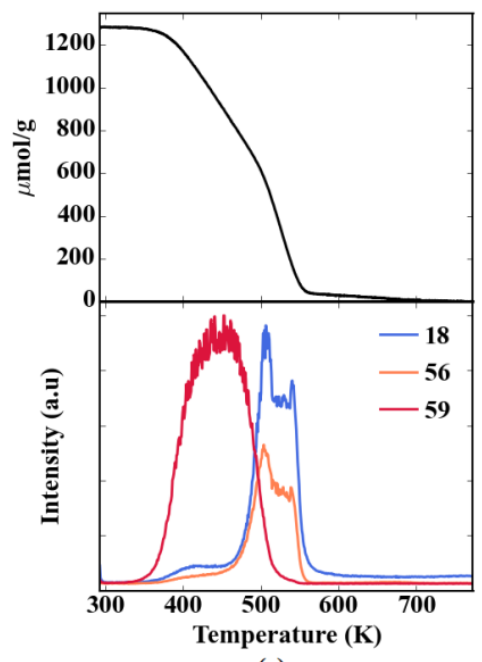

(c)

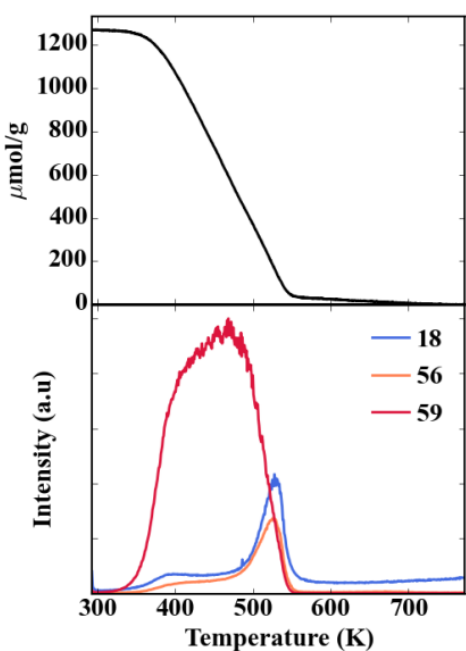

(d)

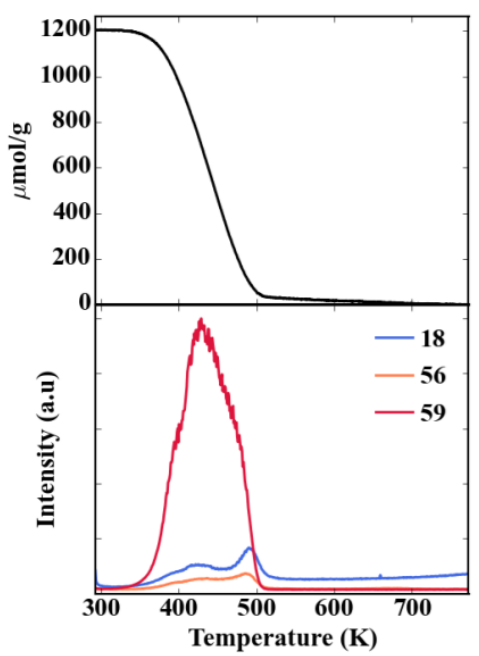

(e)

Figure 8. TPD-TGA results for 2-methyl-2-propanol on (a) SiBEA, (b) SnBEA (c) Li-BEA, (d) Na-BEA, and (e) K-BEA. 


\begin{tabular}{|l|l|l|l|l|}
\hline Catalyst & Li-BEA & K-BEA & SiBEA & SnBEA \\
\hline Conversion & $<1 \%$ & $<1 \%$ & $4.5 \%$ & $35.8 \%$ \\
\hline
\end{tabular}

Table 1. HMF conversion for reductive etherification in 2-propanol at $180^{\circ} \mathrm{C}$ and $1000 \mathrm{psi}$. The feed was $1 \mathrm{~g} \mathrm{HMF}$ in $100 \mathrm{~mL}$ 2-propanol, with flow rate of $0.2 \mathrm{ml} / \mathrm{min}$ and a catalyst loading of $0.1 \mathrm{~g}$. 